\title{
Research for Control Method of Brush-Less DC Motor Using Bi-Directional Quasi-Z-Source Converter in EVs
}

\author{
Li Zhu ${ }^{a}$, Mingwei Ren ${ }^{b}$ \\ School of electrical and information engineering, Jiangsu University, Zhenjiang 212013, China \\ a13775356918@163.com, bmwren_2000@163.com
}

Keywords: Quasi-Z-source converter, BLDCM, Square-wave, Sine-wave

\begin{abstract}
A novel brush-less DC motor, with two drive methods based on bi-directional quasi-Z-source converter is studied in this paper. The parameters of quasi-Z-source network are respectively designed in square-wave and sine-wave drive methods. The BLDCM control system that applies to micro electric vehicle is also proposed in this paper. It is more suitable than the traditional control system. The performance of speed and torque can be improved by utilizing the shoot-through state to boost and compensate the DC voltage. It can effectively broaden the running conditions of EVs. The simulation results are analyzed in detail to demonstrate the validity, veracity and instantaneity of the system.
\end{abstract}

\section{Introduction}

Generally, the research for a high-performance motor drive control system with low costs, small size and light weight, has great significance to the rapid development of electric vehicles (EVs). Brushless DC motor (BLDCM) has been widely used in micro electric cars. However, the battery voltage of electric vehicles often falls abnormally in some conditions (such as climbing, acceleration, etc.), which will decline the motor speed and torque performance, and ultimately limit the application of EVs. The traditional way to solve the problem is to add a bidirectional Boost DC-DC circuit between the battery and the motor drive circuits. It can effectively compensate the voltage drop by raising the DC bus voltage. But these circuits reduce the efficiency of the system and increase the cost because of the complex structure, poor reliability. Z-source converter, with the single stage topology and unique boosting voltage characteristics, can take the place of bidirectional Boost DC-DC circuit.

In this paper, the parameters of quasi-Z-source network are respectively designed in square-wave and sine-wave drive methods. Inductance and capacitance of two drive systems are designed and optimized without changing the hardware circuits to implement four working modes which can be switched smoothly in different working conditions. The experiment results show that the control system is feasible, effective and correct.

\section{Circuit Topology}



Fig. 1 Topology of the main circuit

The circuit topology is shown in Fig.1. It consists of DC power, quasi-Z-source network,

three-phase bridge and BLDCM. The boosted DC bus output voltage Vpn, in quasi-Z-source network, can be expressed as

$$
V_{p n}=\frac{V_{d c}}{1-2 D_{0}}
$$


where $\mathrm{D}_{0}$ is the shoot-through duty ratio, $\mathrm{Vdc}$ is $\mathrm{DC}$ output voltage. $\mathrm{D}_{0}$ can be calculated as

$$
D_{0}=\frac{t_{0}}{T_{s}}
$$

Where Ts is the switching cycle, t0 is the shoot-through time in a switching cycle.

BLDCM can operate in larger torque or higher speed by inserting shoot-through state into the three-phase bridge without the effect on the normal motor drive. Also, it can resist the abnormal voltage drop effectively, that will obviously enlarge the driving conditions and application of EVs.

In order to make the analysis more simplified, the winding inductance of the BLDCM and the transition process of the full control switch are not considered. According to the equivalent drive circuit of brushless DC motor,we get:

$$
V_{p n}-2 V_{T}=E+2 r I_{a}
$$

Where the Vpn is the DC bus voltage, VT is the tube voltage drop of switching elements, $\mathrm{E}$ is the counter electromotive force of the motor, $\mathrm{R}$ is the resistance of each phase winding, Ia is the armature current.

The counter electromotive force of the motor $\mathrm{E}=\mathrm{Ce} \Phi$, so the formula (3) can be written as,

$$
\begin{gathered}
I_{a}=\frac{V_{p n}-2 V_{T}-E}{2 r} \\
n=\frac{V_{p n}-2 V_{T}-2 r I_{a}}{C \Phi}
\end{gathered}
$$

From formula (4) and (5), we know that the speed and torque performance of BLDCM can be improved by increasing the DC bus voltage Vpn. So, combined with the quasi-Z-source inverter step-up characteristics. If the DC input voltage Vdc can not meet the torque and speed demand of EVs, the DC bus voltage Vpn can be improved by inserting an appropriate shoot-through duty cycle $\mathrm{D}_{0}$ to satisfy the demands. After adding D0, according to the formula (1), the average voltage of the motor power supply can be expressed as,

$$
\bar{V}=\frac{V_{d c}}{1-2 D_{0}} \cdot\left(1-D_{0}\right)=\frac{1-D_{0}}{1-2 D_{0}} \cdot V_{d c}>V_{d c}
$$

From formula (6), the average voltage of the DC bus is larger than the DC input supply after adding shoot-through state. Therefore, when the chopping duty cycle $\mathrm{D}$ or modulation $\mathrm{M}$ of the control system reaches the maximum, shoot-through duty cycle D0 can be added to the three-phase bridge to meet different needs of electric vehicles.

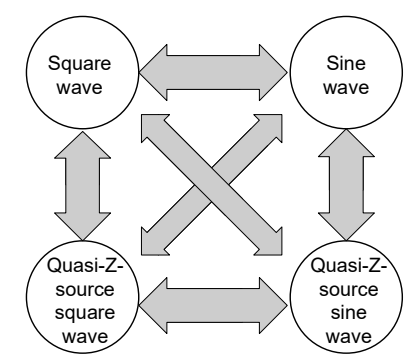

Fig.2 Flexible switching of four operating modes

As shown in Fig.2, four working modes, including traditional square-wave mode and sine-wave mode, novel quasi-Z-source square-wave boost mode and quasi-Z-source sine-wave boost mode, can be switched flexibly between each other according to the real-time traffic and characteristics of every working mode.

\section{Bi-Directional Quasi-Z-Source Square-Wave Control System}

Unlike the traditional square-wave drive which needs to simultaneously control the conduction of two switch tubes each time, the quasi-Z-source square-wave drive has to control the third switch tube to add shoot-through state into the circuit. So, the DC bus voltage can be improved to meet different driving requirements such as high speed or high torque. For example, when phase A and phase $\mathrm{C}$ are 
in control, the current flows into phase A is positive, and the switching tubes Q1, Q2 and Q4 need to be controlled at this time. As shown in Fig.3 (a), Q1 and Q2 are always on while Q4 is chopping. When Q4 is on, the bridge arm of Q1 and Q4 is shorted to get shoot-through state required for boosting the z-source network. If Q4 turns off, Q1 and Q2 operate normally to drive BLDCM. So, the duty cycle of Q4 can be viewed as shoot-through duty cycle D0. During the time of Q4 is off, the BLDCM is driven normally with the modulation cycle of 1-D0. Similarly, when phase A and phase B are in control, if the current flows into phase A is positive, Q1 and Q6 are always on while Q3 is chopping at this time. So that the shoot-through state is distributed averagely to the six-switch tube, balancing the loss of each switch.

In order to avoid the abnormal working state in light loads, switching tube Q7 must be driven by a driving signal that complements the shoot-through signal. In other words, when the bridge circuit is shorted by the shoot-through state, the driving signal of Q7 must be a low level. As shown in Fig. 3 (b), the driving signal of Q7 can be obtained from Q1 to Q6 by some logic operations.



Driving signal of Q1 to Q6

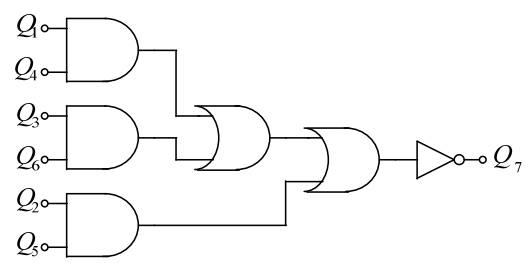

(b) Driving signal of Q7

\subsection{Work States of System}

Fig.3 Driving signals of quasi-Z-source square-wave

The system has a direct short condition, considering the traditional working conditions, there are three work states. Effective time work state, shoot-through time work state and chopping time work state, are respectively presented in Fig.4.

Fig.4 (a), is the state of effective time acting on BLDCM, the switching tubes Q5, Q6 and Q7 are on, the higher DC bus voltage is caused by quasi-Z-source network to drive the motor, where energy from the DC side flows into three-phase winding of motor. Meanwhile, DC power Vdc and inductor L1 together charge capacitor $\mathrm{C} 1$, and inductor L2 charges C2. The voltage of L1 and L2 is the same, so the voltage of $\mathrm{C} 1$ is higher than $\mathrm{C} 2$ because of DC power Vdc. If Q2 also turns on at this time, Q7 must be turned off directly, then the three-phase inverter bridge circuit will be in the state of shoot-through shown in Fig.4 (b)

In Fig.4 (b), Q2 and Q5 are shorted while Q7 is off. inductor L2 is charged by capacitor C1, inductance L1 is charged by capacitance $\mathrm{C} 2$ and dc power Vdc, which are in series, preparing for the next voltage boost. The longer the direct short time, the higher the voltage rises. At this time, the dc side energy does not flow into the motor, and current flows to windings of phase $\mathrm{B}$ and phase $\mathrm{C}$ through the switch tube Q2 and Q6.

If the DC power $\mathrm{Vdc}$ is higher enough to supply power to motor whose speed or torque demands is in a low level, as shown in Fig.4 (c), the system will be in the chopping time which is similar to the

traditional on-pwm driving method of square-wave system. Take Q5 and Q6 as an example, Q5 of up bridge is always on while Q6 of down bridge is chopping all the time. Q7 can be eitger on or off, the work state of the system is similar to Fig. 4 (a). If Q6 is off when it is chopping, as shown in Fig.4 (c), the DC bus voltage is not boosted by quasi-Z-source, and there is no DC energy flows to the motor, the current of phase B and C is continued by the switch tubes Q5 and Q3.

Thus, the proposed square-wave system can switch the normal drive of BLDCM to DC bus voltage boosting of the quasi-Z-source-network freely 


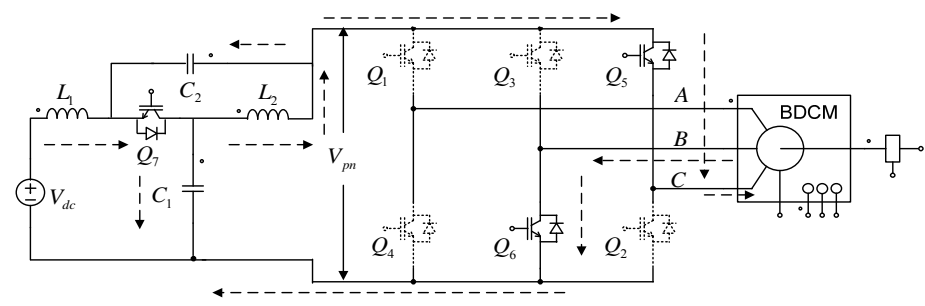

(a) Work states of effective time

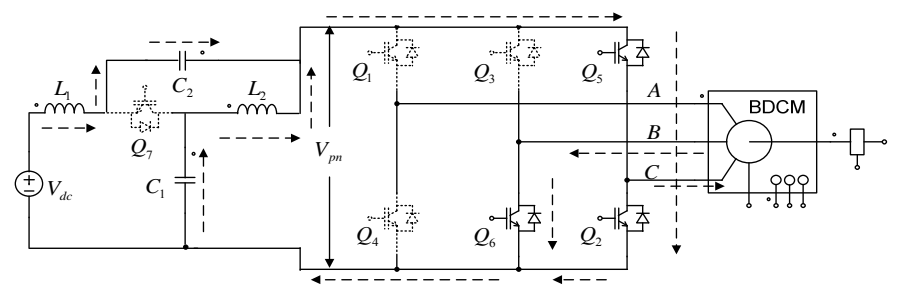

(b) Work states of shoot-through time

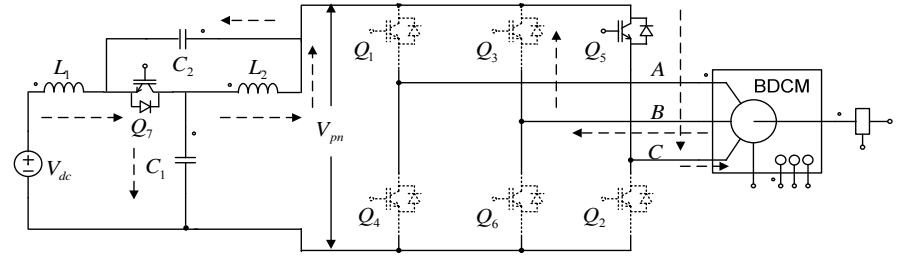

(c) Work states of chopping time

Fig.4 Work states of square-wave system

\subsection{Parameters Calculation of Quasi-Z-Source Network in Square-Wave System}

As shown in Fig.5, in shoot-through state, the current of two inductors will rise up as they are charged by two capacitors whose voltage will drop down. While the current of two inductors will drop down as they must supply power to motor and charge two capacitors in non- shoot-through state, and similarly the voltage of two capacitors will rise up because of being charged by two inductors. In Fig.5, D0 is shoot-through duty cycle, IL and UC are respectively current of inductors and voltage of capacitors, $\Delta \mathrm{iL}$ and $\Delta \mathrm{uC}$ are respectively ripple of the inductor current and the capacitor voltage.

\subsubsection{Design of Inductance Parameters}

Fig. 5 shows that, in a switch period $\mathrm{T}$, action time of the through short-circuit state is $\mathrm{T} 0$, the inductor ripple current $\Delta \mathrm{iL}$ is set to $\mathrm{x} \%$ of the inductor current IL, in short-circuit time.

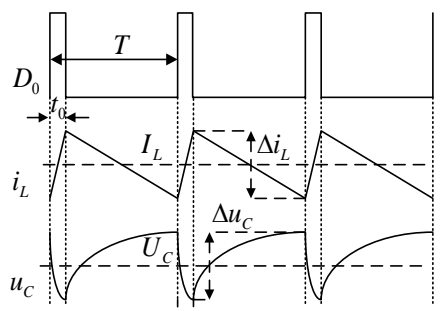

Fig.5 Waveform about quasi-Z-source network in square-wave driving

$$
V_{L}=L \frac{\Delta i_{L}}{t_{0}}=L \frac{x \% \cdot I_{L}}{D_{0} \cdot T}
$$

Inductance should be as far as possible in the continuous mode, the inductor current waveform is shown in Fig.5, when the inductor current IL is the minimum value of Imin, assuming the inductor in the critical mode,

$$
\Delta i_{L}=2 I_{\min }
$$

If defined minimum current value acquired in brush-less DC motor is $10 \%$ of the power, and the consideration of system efficiency $\eta$, then for brush-less DC motor for power of $\mathrm{P}$, 


$$
I_{\min }=\frac{0.1 P}{\eta \cdot V_{d c}}
$$

Where Vdc is the DC power supply voltage, combined formula (7), formula (8) and formula (9) can get,

$$
L=\frac{V_{L} \cdot t_{0} \cdot \eta \cdot V_{d c}}{0.2 P}
$$

According to the characteristics of the quasi-Z-source network, the voltage at both ends of the two inductor is equal to the voltage $\mathrm{VC} 1$ of the capacitor $\mathrm{C} 1$ at both ends of the straight time.

$$
V_{C 1}=\frac{1-D_{0}}{1-2 D_{0}} \cdot V_{d c}
$$

So, formula (11) can be written as:

$$
L=\frac{D_{0}\left(1-D_{0}\right) \cdot \eta \cdot V_{d c}^{2}}{0.2\left(1-2 D_{0}\right) P \cdot f}
$$

That is, the design of the electric induction is greater than or equal to the value of the formula (12). Where $\mathrm{f}$ is switching frequency of the shoot-through duty ratio, $\eta$ is the system efficiency, $\mathrm{P}$ is brush-less DC motor power, D0 is shoot-through duty cycle, Vdc is DC input voltage.

\subsubsection{Design of Capacitance Parameters}

Steady state, in through time the size of the capacitive current is equal to the size of the inductor current and assumptions in the maximum capacitance current ICmax, the capacitor ripple voltage $\triangle \mathrm{UC}$ is $\mathrm{y} \%$ of capacitor voltage $\mathrm{VC}$, in the straight time $\mathrm{t} 0$,

$$
I_{C \max }=I_{L \max }=C \frac{\Delta U_{C}}{t_{0}}=C \frac{y \% \cdot V_{C}}{D_{0} \cdot T}
$$

Maximum capacitor current and inductor current is obtained when the motor reaches a peak power, so consider 1.5 times the motor overload and circuit system efficiency $\eta$,

$$
I_{C \max }=I_{L \max }=\frac{1.5 P}{\eta \cdot V_{d c}}
$$

Combination formula (13) and formula (14) can be obtained,

$$
C=\frac{1.5 D_{0} \cdot P}{y \% \cdot \eta \cdot V_{C} \cdot V_{d c} \cdot f}
$$

According to the characteristics of the quasi-Z-source network, it can be known that the voltage stress of the capacitor $\mathrm{C} 1$ and $\mathrm{C} 2$ is different, so the voltage parameters are different in the design of the capacitor:

$$
\begin{gathered}
C_{1}=\frac{1.5 D_{0}\left(1-2 D_{0}\right) \cdot P}{\left(1-D_{0}\right) y \% \cdot \eta \cdot V_{d c}^{2} \cdot f} \\
C_{2}=\frac{1.5\left(1-2 D_{0}\right) \cdot P}{y \% \cdot \eta \cdot V_{d c}^{2} \cdot f}
\end{gathered}
$$

Where $\mathrm{f}$ is switching frequency of the shoot through duty ratio, $\eta$ is the system efficiency, $\mathrm{P}$ is brush-less DC motor power, D0 is shoot-through duty ratio, Vdc is DC input voltage, y is capacitor voltage ripple coefficient.

\subsection{Z-Source Square-Wave Control}

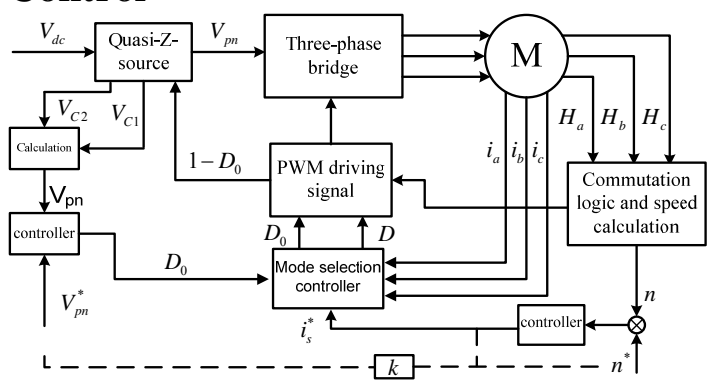

Fig.6 Principle block diagram of quasi-Z-source square-wave control system

As shown in Fig. 6 is a bi-directional quasi-Z-source square-wave control principle block diagram. The control system has two operating modes, the quasi-Z-source square-wave boost mode and the traditional on-pwm chopping mode. When the DC voltage dips or fault can not meet the motor speed 
and torque demand, mode selection controller chooses quasi-Z-source boost mode. As shown the dotted line in Fig.6, the given value Vpn* of the DC bus voltage is selected according to the different speed torque requirements at this time. Vpn* and the actual DC bus voltage Vpn are adjusted by PI output shoot-through duty cycle D0, it used to regulate the DC bus voltage to achieve closed-loop control of $\mathrm{DC}$ bus voltage. And at this time need to ensure that the chopping duty cycle $\mathrm{D}=1$, that is, the inverter part is not chopped. According to the formula (6), the average value of the DC bus voltage is always greater than the DC power supply voltage as long as the direct duty cycle is added; When the DC bus voltage is enough to satisfy the motor drive demand, the mode selection controller selects the traditional on-pwm chopping mode, and shoot-through duty cycle D0 output is zero, and the chopping duty cycle D changes from 1 to 0 at present.

Due to the shoot-through state, the DC bus is short circuit, Vpn is 0 , in the non-shoot-through state, Vpn returns to the normal value, not zero, the DC bus voltage is continuous high voltage pulse wave, and it is difficult to directly detect the maximum value of Vpn. However:

$$
V_{p n}=V_{C 1}+V_{C 2}
$$

So we can calculate the value of Vpn by detecting voltage VC1 and VC2 of the capacitance $\mathrm{C} 1$ and $\mathrm{C} 2$ respectively, indirectly detect the value of real-time Vpn.

\section{Bi-Directional Quasi-Z-Source Sine-Wave Control System}

The method of adding the direct current to the sine-wave is different from the square-wave drive. shoot-through state can be inserted in the three-phase bridge with the method of leading or delaying the switch tubes, as shown in Fig.7, using SVPWM modulation, the shoot-through zero vector is divided into four parts to insert the traditional zero without occupying the effective time vector. It means the direct current can be inserted into the upper and lower power switching devices of the bridge arms, each time only one phase is inserted the direct current, that is, each time only one phase is shorted. It will not change the original switching frequency.

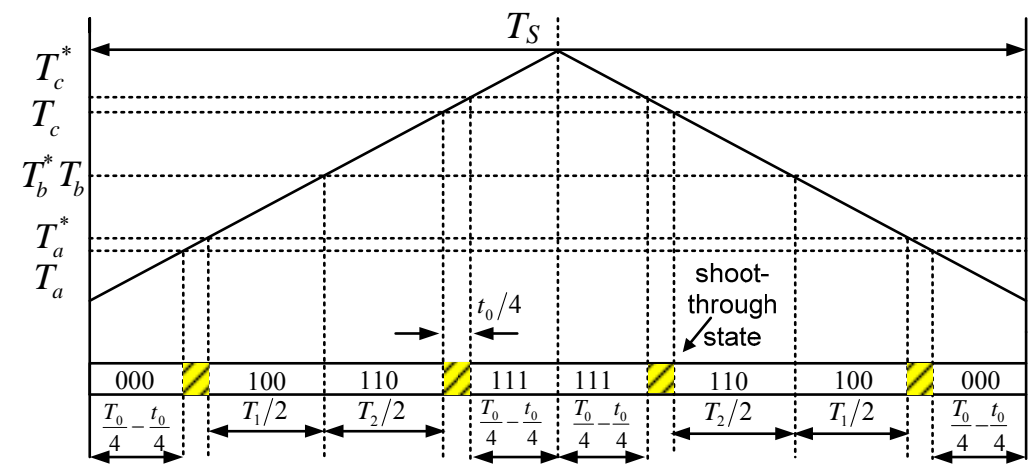

Fig.7 The method of inserting the direct current when the sine-wave drives

According to the Fig.7, the current change time of the upper and lower bridge is different, the upper bridge arm is:

$$
\left\{\begin{array}{l}
T_{a}=T_{0} / 4-t_{0} / 4 \\
T_{b}=T_{0} / 4+T_{1} / 2 \\
T_{C}=T_{0} / 4+T_{1} / 2+T_{2} / 2
\end{array}\right.
$$

The lower bridge arm is:

$$
\left\{\begin{array}{l}
T_{a}^{*}=T_{0} / 4 \\
T_{b}^{*}=T_{0} / 4+T_{1} / 2 \\
T_{c}^{*}=T_{0} / 4+T_{1} / 2+T_{2} / 2+t_{0} / 4
\end{array}\right.
$$

And: 


$$
\left\{\begin{array}{l}
T_{0}=T_{s}-T_{1}-T_{2} \\
T_{1}=\left(\frac{3}{2} U_{\alpha}-\frac{\sqrt{3}}{2} U_{\beta}\right) \frac{T_{s}}{V_{p n}} \\
T_{2}=\sqrt{3} U_{\beta} \frac{T_{s}}{V_{p n}} \\
t_{0}=D_{0} \cdot T_{s}
\end{array}\right.
$$

In formula (21) $, \mathbf{U}_{\alpha}, \mathbf{U}_{\beta}$ are two components of the reference vector $\mathbf{U}_{\text {ref }}$ decomposition in two-phase stationary coordinates. $\mathbf{T}_{1}, \mathbf{T}_{2}$ are the action time of the effective vectors. $\mathbf{T}_{0}$ is the traditional zero vector time, t0 is the action time of shoot-through zero vector, and $t_{0}$ cannot be more than $\mathrm{T}_{0}$.

So, there is no dead time setting in three-phase bridge, no tube short-circuits. It will improve the anti-jamming ability and the stability of the BLDCM controller. Because there is no dead time, the output harmonic will be reduced, the system efficiency will also be increased.

\subsection{System Operating Status}

Quasi-Z-source system driven by sine-wave a lso has three working states:

Fig.8 (a) is an effective time state, the switch tubes Q1, Q2, Q3 and Q7 are on, DC input voltage $\mathrm{Vdc}$ and two inductors in series provide higher DC link voltage for the motor, DC energy smoothly flows into the three-phase winding of the motor, motor drives normally. At the same time, DC input voltage $\mathrm{Vdc}$ and the inductor L1 are charging the capacitor $\mathrm{C} 1$, inductance L2 is charging the capacitor $\mathrm{C} 2$.

When the $\mathrm{Q}_{5}$ is on, $\mathrm{Q}_{2}$ disconnect the motor into the traditional continuous time state flow, as shown in Fig.8 (b). At this time, the quasi-Z-source network is still in the boost, DC input voltage $\mathrm{V}_{\mathrm{dc}}$ and two inductors in series provide higher DC link voltage for motor but the DC energy does not flow into the moto. The current of three-phase winding of the motor is continued by the switch tubes Q1, Q3 and Q5. DC input voltage Vdc and inductance L1 charge the capacitor C1, inductance L2 continues to charge the capacitor $\mathrm{C} 2$.

If at the time Q5 is on, Q7 is off, and Q2 is delayed, the motor goes into shoot-through zero vector state shown in Fig.8 (c). At this time, Q2 and Q5 are shorted, the capacitor C1 is charging the inductor $\mathrm{L} 2$ when capacitor $\mathrm{C} 2$ and Vdc charge the inductor L1, preparing for the next boost. At this time DC energy does not flow into the motor and the current of the three-phase winding of the motor is continued by the switch tube Q1, Q2, Q3 and Q6.

Thus, in the state of the traditional continuous flow time in Fig.8 (b) and the shoot-through time in Fig. 8 (c), the energy does not flow into the motor while the current of the winding is continued by the switch tubes. So free switching between motor drive and quasi-Z-source network boost can be realized by guiding in advance and delaying shutdown of a switch tube. 


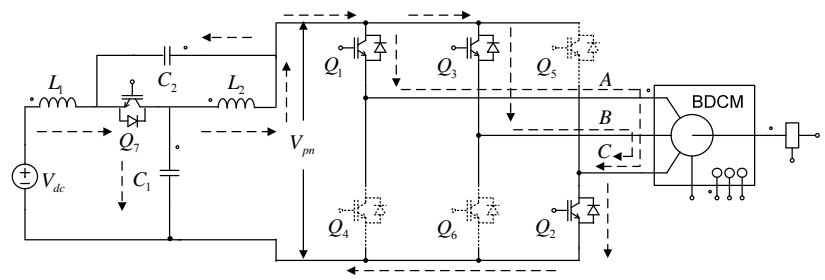

(a) Effective time action state

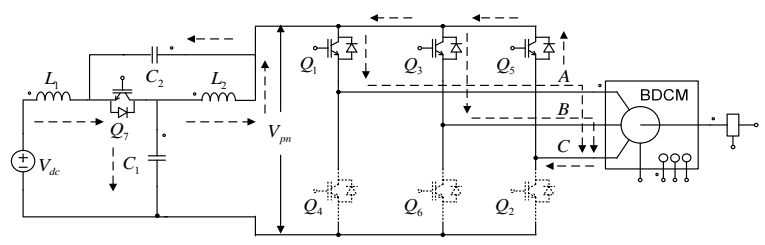

(b) The state of the traditional continuous flow time



(c)Through time action status

Fig. 8 Three working states of sine-wave drive

\subsection{Calculation of Parameters of Quasi Z Source Network}

As shown in Fig.9, take the first sector as an example, being in SVPWM modulation, the rotation of the reference vector is composed of two adjacent active vectors and the traditional zero vector. With the changes of the rotation angle of the reference vector, the action time of two effective vectors and the traditional zero vector are also changing constantly. From Fig.9, the inductor current in two effective vector time declines in the most. At this time the current ripple is maximum. when the reference vector is rotated to the middle position of the first sector, namely 30 degrees, the sum of effective vector time, $(\mathrm{T} 1+\mathrm{T} 2)$ is maximum, the pattern amplitude value is expected to be maximum.



Fig.9 The key components of quasi-Z-source network

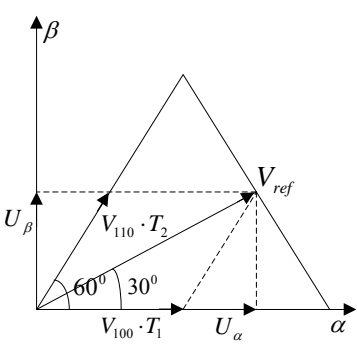

Fig.10 First sector vector composite image

$\mathrm{iL}$ and $\mathrm{uC}$ are inductor current and capacitor voltage in the quasi-Z-source network. IL and UC are the DC components of inductance current and capacitance voltage. $\Delta i_{L}$ and $\Delta u_{C}$ are the maximum ripple current of inductance and the maximum ripple voltage of capacitance in a cycle time.

\subsubsection{Design of Inductance Parameters}

As shown in Fig.9, the maximum inductor current ripple appears when the continuous effective vector $(100,110)$ is active, the action time $\Delta \mathrm{t}=(\mathrm{T} 1+\mathrm{T} 2) / 2$. In effective time $\Delta \mathrm{t}$, the maximum inductor ripple current is set as $\mathrm{x} \%$ of the inductor current $\mathrm{IL}$, then

$$
V_{L}=L \frac{\Delta i_{L}}{\Delta t}=L \frac{2 \Delta i_{L}}{T_{1}+T_{2}}=L \frac{2 \cdot x \% \cdot I_{L}}{T_{1}+T_{2}}
$$


As shown in Fig.10, the effective vector 100 and 110 respectively work T1 and T2 to synthesize the reference vector Vref. The electrical position angle of Vref is 30 degrees at this time.

$$
\left\{\begin{array}{c}
\mathrm{U}_{\alpha}=\mathrm{V}_{\text {ref }} \cos 30^{\circ}=\frac{\sqrt{3}}{2} \mathrm{~V}_{\text {ref }} \\
\mathrm{U}_{\beta}=\mathrm{V}_{\text {ref }} \sin 30^{\circ}=\frac{1}{2} \mathrm{~V}_{\text {ref }}
\end{array}\right.
$$

Define the modulation ratio $\mathrm{M}=2 \mathrm{Vref} / \mathrm{Vpn}$ and combining with formula (21) and (23), the following formula can be obtained:

$$
T_{1}+T_{2}=\frac{\sqrt{3} M \cdot T_{S}}{2}
$$

Inductance needs to work in a continuous mode. If the maximum ripple current is continuous, then the current will be continuous elsewhere. So only to consider the continuous case at maximum ripple current. As shown in Fig.9, assuming the inductor current as the minimum Imin, inductance should be in the critical work mode, that is,

$$
\Delta i_{L}=2 I_{\min }
$$

The minimum inductance current value is defined to obtain under the brush-less DC motor $10 \%$ of the power with considering the system efficiency of $\eta$. So, the power P of the brush-less DC motor can be seen as the load, there is,

$$
I_{\min }=\frac{0.1 P}{\eta \cdot V_{d c}}
$$

Vdc is the DC input voltage. The formula (27) can be obtained by combining with the formula (22), (24), (25) and (26):

$$
L=\frac{\sqrt{3} M \cdot \eta \cdot V_{d c} \cdot V_{L} \cdot T_{S}}{0.8 P}
$$

According to the working characteristics of quasi-Z-source network, both ends of the inductive voltages are equal to the voltage VC2 of the capacitor $\mathrm{C} 2$ in the non-shoot-through time. Then

$$
V_{C 2}=\frac{D_{0}}{1-2 D_{0}} \cdot V_{d c}
$$

Therefore, according to formula (28), the formula (27) can be written as

$$
L=\frac{\sqrt{3} D_{0} \cdot M \cdot \eta \cdot V_{d c}^{2}}{0.8\left(1-2 D_{0}\right) \cdot P \cdot f}
$$

Where $\mathrm{f}$ is the switching frequency of SVPWM, $\eta$ is the efficiency of system, $\mathrm{P}$ is the power of a brush-less DC motor, D0 is the shoot-through duty cycle, Vdc is the DC input voltage, $\mathrm{M}$ is the SVPWM modulation.

Comparing the formula (12) inductance value of square-wave drive, the sine-wave drive of the formula (29) is relatively small, and shoot-through duty is smaller than D0. Then this advantage of sine-wave drive is more obvious.

\subsubsection{Design of Capacitance Parameters}

Unlike square-wave driving, Fig.9 shows that in a period of Ts, the capacitor ripple voltage fluctuation is four times which is four times of square-wave drive, and the time of each pulse is t0/4. So similar to the square-wave drive, capacitance values of a sine-wave drive are:

$$
\begin{gathered}
C_{1}=\frac{1.5 D_{0}\left(1-2 D_{0}\right) \cdot P}{4\left(1-D_{0}\right) y \% \cdot \eta \cdot V_{d c}^{2} \cdot f} \\
C_{2}=\frac{1.5\left(1-2 D_{0}\right) \cdot P}{4 y \% \cdot \eta \cdot V_{d c}^{2} \cdot f}
\end{gathered}
$$

Compared to square-wave drive, when the switch frequency and the duty cycle of shoot-through are the same, the capacitance value is reduced to $1 / 4$ of the original one. It reduces the volume of the capacitor. This is the advantage of the quasi-Z-source sine-wave drive.

\subsection{Bi-Directional Quasi-Z-Source Square-Wave Control}

The control strategy of $\mathrm{id}=0$ is adopted in this paper. As shown in figure 11, three-phase currents id and iq are obtained after Clarke and Park transformations. The outer ring of the motor is speed loop. 
The output of speed controller is the given current iq*. id and iq are regulated by PI to get output ud and uq respectively, then go to the inverter after Park inverse transform, completed the double-loop control of the motor speed torque.

The control system has two work modes: Z-source boost mode and traditional sine-wave drive mode. The switch of two patterns is achieved by the mode selection controller. It is shown in Fig.11 that DC bus voltage Vpn* is set according to the demand of the motor speed torque, and the output of the duty cycle D0 is controlled by the given value and actual value. When the actual value Vpn is less than the given value $\mathrm{Vpn} *$, namely the DC bus voltage does not meet the demand of motor speed torque, the Z-source boost mode is chosen by the mode selection controller to change the direct duty cycle to increase the DC bus voltage. If the actual value Vpn satisfies the motor drive, the traditional sine-wave drive mode will be chosen and the output duty ratio D0 is zero.

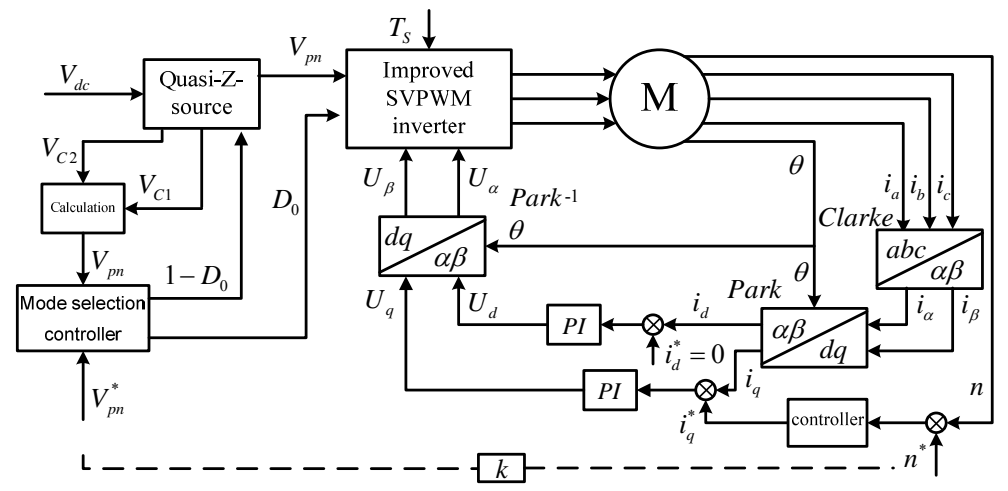

Fig.11 Quasi -Z-source sine-wave control

\section{Experiments}

Table 1 Parameters of the experimental system

\begin{tabular}{lclll}
\hline \hline Parameter name & Value & Parameter name & Value \\
\hline $\mathrm{C}_{1} / \mu \mathrm{F}$ & 220 & $\mathrm{C}_{2} / \mu \mathrm{F}$ & 1000 \\
\hline Type of Motor & 80BL89S50-445TF0 & $\mathrm{L}_{1}, \mathrm{~L}_{2} / \mathrm{mH}$ & 1.0 \\
\hline Rated speed(r/min) & 4000 & Rated current/A & 15 \\
\hline Rated voltage/V & 48 & Number of pole pairs $\mathrm{P}$ & 3 \\
\hline Rated power/W & 500 & MOS & IRFP250 \\
\hline Rated torque $(\mathrm{N} \cdot \mathrm{m})$ & 1.2 & Switching frequency/kHz & 10 \\
\hline \hline
\end{tabular}

To verify the control system in the paper, the experimental prototype of the rated power $500 \mathrm{~W}$ is constructed. The specific parameters of the prototype are shown in Table 1.

\subsection{Experimental Verification of Bi-Directional Quasi Z Source Square-Wave Drive}

As shown in Fig.12, the system works in quasi-Z-source square-wave boost mode, where the four switch drive signals, each switch shares the same amount of shoot-through and the average loss of each switch. If the six-switch tube combination is exactly the continuous shoot-through state.

Fig. 13 is the waveform of the various components corresponding to the quasi-Z-source network, the power supply voltage is $24 \mathrm{~V}$, shoot-through duty cycle is 0.2 , at this time the DC bus voltage Vpn rose to $40 \mathrm{~V}$ or so, to meet the theoretical calculation. Inductor current IL in the shoot-through time decreased by non-shoot-through time up, working in continuous mode, to meet the design requirements.

In Fig.14, the waveform is obtained by using quasi-Z-source square-waveform controller, and the system is still in quasi-Z-source square-wave boost mode. DC bus voltage is boosted to $20 \mathrm{~V}$, the shoot-through quantity inserting into the system does not affect the normal driving of the motor according to the motor current waveform ib. In order to verify the quasi-Z boost mode can effectively resist the abnormal drop of DC power supply. In Fig.15, when the DC bus voltage value is set as $22 \mathrm{~V}$, 
before DC input voltage drops from $18 \mathrm{~V}$ to $15 \mathrm{~V}$, the $\mathrm{DC}$ bus voltage $\mathrm{Vpn}$ has rised to the given voltage $22 \mathrm{~V}$. After the voltage drop $0.4 \mathrm{~s}$ or so, DC bus voltage is again stabilized at $22 \mathrm{~V}$, which verifies that system has strong performance of abnormal anti-voltage drop.

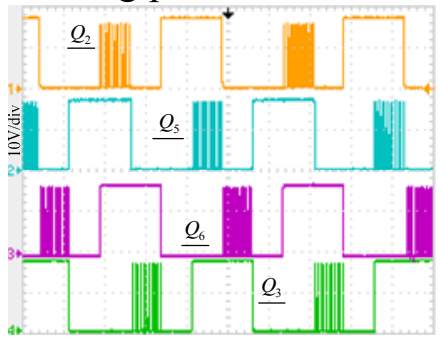

Fig.12 Square-wave drive signal

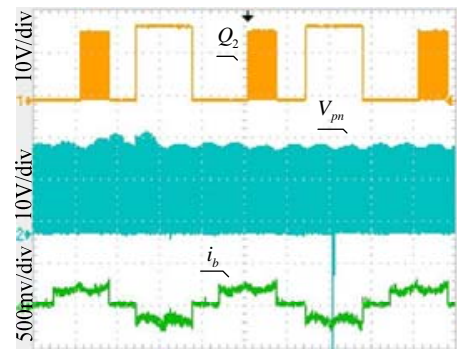

Fig.14 Quasi-Z-source square-wave drive

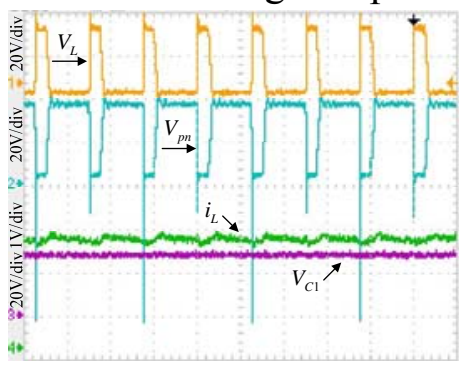

Fig.13 Quasi-Z-source network



Fig.15 Power supply voltage dip

\subsection{Experiments for Bi-Directional Z-Source of Sine-Wave Drive}

In the experiments, the upper tubes of three-phase bridge are driven by traditional SVPWM, and the lower tubes delay to turn off or turned on in advance by program processing, so the upper and lower tubes have simultaneous conduction state. The waveforms of the upper tubes Q1, Q3, Q5 and the lower tube Q2 are shown in Fig.16. It can be seen that Q2 and Q5 have shoot-through and short-circuit state in a switching cycle. To be sure, within a switching cycle, Q1 and Q4, Q3 and Q6 equally have shoot-through states. The Quasi-Z-source waveforms of each device driven by sine-wave are shown in Fig.17. When the shoot-through duty cycle is 0.2 and supply voltage is $24 \mathrm{~V}$, the DC bus voltage Vpn basically increases to theoretical value $40 \mathrm{~V}$.

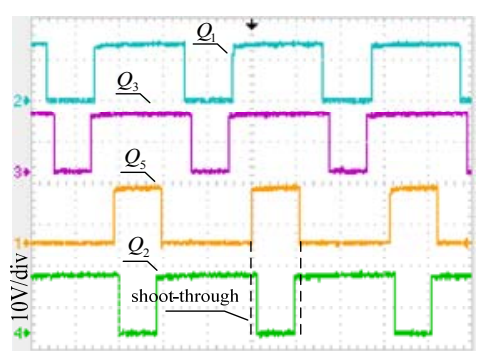

Fig.16 Sine-wave drive signal



Fig. 17 Waveform of quasi-Z-source network

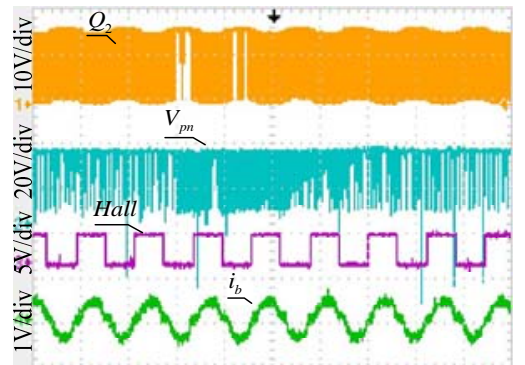

Fig.18.Quasi-Z-source sine-wave drive

As shown in Fig.18, the system works in a quasi-Z-source sine-wave voltage boost mode. The DC bus voltage is in the boost state, and the winding current ib of BLDCM is very close to the sine-wave. the normal drive of the motor will not be affected by adding the shoot-through state. The integrated control of the brush-less DC motor with quasi-Z-source boosting is realized.

\subsection{Switch the Drive Modes}

In this paper, the square-wave is used to start, the system can choose a variety of operating modes according to the real operating conditions after detecting the motor speed and the electrical position angle. 
Fig.19 (a) is a waveform of the system to capture the transition from traditional on-pwm square-wave drive mode to the quasi-Z-source boost mode. From the chart, when the DC bus voltage Vpn higher, the drive waveform of switch tube Q2 is on-pwm mode. With the decline of the Vdc, DC bus voltage Vpn is also slow down, the on-pwm chopping duty cycle reduces to zero, that is not chopped. After four cycles, the Vpn is not enough to meet the motor speed torque, then model selection controller switches the system to quasi-Z-source boost mode smoothly, DC bus voltage Vpn increases after adding the shoot-through state, the motor speed is increased slightly.

Other work modes conversion is respectively shown in Fig.19 (b), (c), (d) and (e). The conversions can be selected according to the advantages and disadvantages of the different drive modes and the real road conditions.

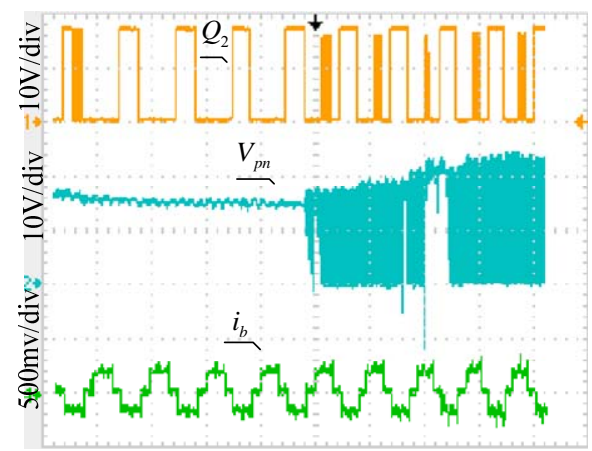

(a) Square-wave to quasi-Z-source square-wave

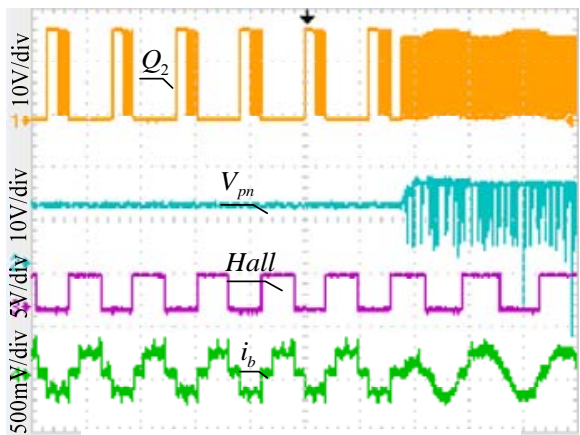

(b) Square-wave to quasi-Z-source sine-wave



(d) Sine-wave to quasi-Z-source

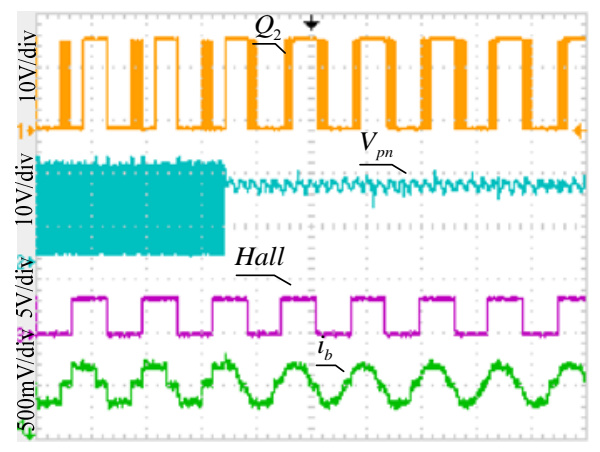

(c) Quasi-Z-source square-wave to sine-wave

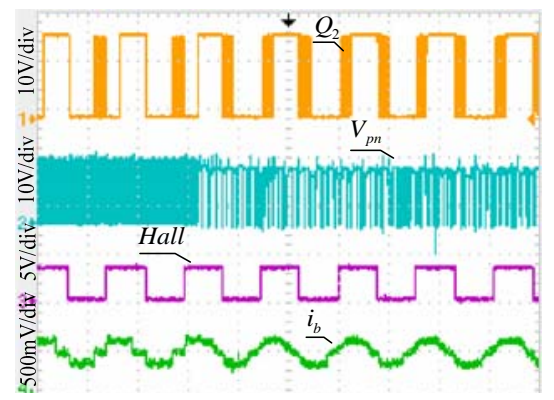

(e) Quasi-Z-source square-wave to quasi-Z-source sine-wave

Fig.19 conversion of work modes

\section{Conclusion}

Bidirectional quasi-z source square wave and bidirectional quasi-z source sine wave control system are proposed. There are four work modes. EVs can be switched to suitable working modes in 
suitable driving conditions to improve their driving performance and expand the applicable driving conditions. There is no dead zone in this system. The abnormal fall of power voltage can be resisted effectively to improve the stability of the system. The system is verified to be effective, accurate and real-time by simulation and experiment. It has a broad application prospect.

\section{References}

[1]. Peng F Z, Shen Miaosen,Kent Holland,et al. Z-source Inverter Control for Traction Drive of Fuel Cell-Battery Hybrid Vehicles[J].IEEE Transactions on Power Electronics, May June,2007, Vol.22, p.1054-1061.

[2]. Peng F Z, Alen Joseph, Jin Wang.Z-source inverter for motor drives[J]. IEEE Transactions on PowerElectronics,2005,20(4): 857-863.

[3]. Liu Mingji, Guo Hanjin and Song Meihong, "Ripple torque analysis and simulation of BLDC motor with different PWM modes," Power Electronics and Motion Control Conference (IPEMC), 2012 7th International, Harbin, 2012, p. 973-977.

[4]. O. Ellabban, J. V. Mierlo and P. Lataire, "A new closed loop speed control of induction motor fed by a high-performance Z-source inverter," Electric Power and Energy Conference (EPEC), 2010 IEEE, Halifax, NS, 2010, p. 1-6.

[5]. Omar Ellabban. Z-Source Inverter for Vehicular Applications. IEEE Transactions on Industrial Electronics. 2011. 